ARoueología Y SOCIEDAD

№ 26, 2013: 407-418

ISSN: 0254-8062

RECIBIDO: 19 / MAR. / 2013

ACEPTADO: 20 / ABR. / 2013

\title{
CUANDO LA IDENTIDAD ES MÁS FUERTE: PRIMERAS EVIDENCIAS MATERIALES DE LA COLECTIVIDAD JUDÍA COLONIAL EN BUENOS AIRES
}

\author{
DR. DANIEL SCHÁVELZON \\ Director del Centro de Aroueología URBANA de LA UniversidAd de Buenos Aires \\ INVESTIGADOR PRINCIPAL DEL CONICET \\ dschavelzon@fibertel.com.ar
}

\section{RESUMEN}

Por primera vez se encuentra en Buenos Aires evidencias materiales de la práctica de la religión judía durante el periodo colonial. El hallazgo de una baldosa en un piso colonial de una casa de clase alta, que tiene grabado en su parte inferior una Estrella de David, permite reflexionar sobre la situación de la población judía en el mundo colonial hispánico.

Palabras Clave: Judíos, Buenos Aires, Estrella de David, periodo colonial.

\section{Abstract}

For the first time in Buenos Aires we had find material evidence of the practice of the Jewish religion during the colonial period. The finding of a tile floor engraved on its underside with a Star of David, from a colonial upper class house, introduced us on the field of the situation of the Jewish population in the Spanish colonial world.

KeYwoRDS: Jews, Buenos Aires, Star of David, colonial period.

\section{PRESENTACIÓN}

Desde hace medio siglo los empujes producidos por la posmodernidad, el procesualismo, los estudios de género, la antidiscriminación racial y la necesidad de entender a las minorías en la arqueología, ha producido avances notables. Ya nadie puede definir la arqueología como se hacía hace un siglo, en el sentido de la búsqueda de las grandes pautas del comportamiento social porque se ha tomado conciencia que de esa manera se caía en una actitud no democrática del pensamiento. De allí que la búsqueda afanosa de las evidencias materiales de las comunidades como la afroamericana nos han abierto caminos insospechados para entender el pasado.

La presencia de población judía o mejor dicho criptojudía en Buenos Aires, en tiempos en que estaba prohibido que la hubiera, no es un tema menor, pero ya la bibliografía ha penetrado en el pro- 
blema de conocer algo de lo que estaba oculto (Avni 1992; Lewin 1939a y b; Johnson 1991; Roth 1959; Liebman 1984). A veces estaba realmente oculta, otras veces sólo disfrazada y otras la misma sociedad era mucho más permisiva de lo que los papeles indicaban hacia afuera: el eufemismo de los cabildantes coloniales de Buenos Aires de llamar «portugueses» a los criptojudíos o judaizantes (término muy interesante por lo poco claro), a veces resulta inusitado. Pero para las autoridades era un problema en la ciudad del siglo XVII: si los expulsaban como correspondía o se los denunciaba a la Inquisición para su castigo, se quedaban sin panaderos, herreros o zapateros, y sin muchos de los que trabajaban la tierra o comerciaban sus frutos, tarea nada grata para los blancos españoles. Los miembros del Cabildo no podían hacerlo ya que ellos mismos se quedaban sin harina, suponiendo que además no hubiese habido contubernio o corrupción en medio de estas operaciones. Las Actas del Cabildo de la ciudad tienen docenas de casos en que la solución siempre fue obviar el caso «por necesidad de la ciudad», siempre disfrazándolos de portugueses lo que era menos grave. Porque cuando querían ser claros e identificar a cada uno, lo hacían.

A primera vista parece que este sistema de complacencia, ocultamiento y disimulo corrupto funcionaba bien y era socialmente aceptado, además que era cierto que desde el norte, desde Brasil y las Antillas llegaba realmente población judía que crecía en la ciudad. La situación de los judíos expulsos de España no fue la misma al inicio de la conquista que un siglo más tarde, en especial en el Caribe y norte del Brasil. En Recife había una sinagoga que funcionó en Pernambuco entre 1630 y 1644 lo que implica un conjunto importante de familias practicantes. No es casual que la primera sinagoga excavada por la arqueología haya sido en Recife -la sinagoga Kahal zur Israel en la Rua do Bom Jesus-, ya que allí en 1642 llegó el primer rabino para una comunidad de casi 600 familias. La presencia de la liberal Holanda como dueños del comercio por el Atlántico en el inicio del siglo xvir hizo que desde allí algunos judíos fueran buscando nuevos rumbos en otras tierras (Bohm 1992; Emmanuel y Emmanuel 1970; García de Prodian 1966; Winitzer 1966).

Esta migración se transformó en un éxodo cuando los portugueses asumieron en 1654 el control de esos territorios, especialmente de Recife y Pernambuco y se dio la orden de expulsión. En las islas cercanas había una amplia población judía establecida en Jamaica, Curacao, Surinam y tantos otros sitios -muchos pequeños por cierto-, incluso con sinagogas construidas. Pero cuando se produjo la partida de Cartagena ya estaba instalado el Tribunal de la Inquisición, por lo que la entrada al continente más lógica y casi única era el puerto de contrabando de Buenos Aires (Lewin 1967; Toribio Medina 1945). Y era el camino razonable para llegar al ansiado Potosí donde había una fuerte comunidad judía trabajando con la plata de las minas. La presencia en América de judíos no era nueva dado que sabemos hoy que los primeros llegaron con los conquistadores mismos, si no llegaron con Colón en 1492 (Liebman 1971; Bohm 1992; Canclini 1992).

Si bien el tema de ese debate en el campo de la historia supera el objetivo de este artículo, cabe mencionar que incluso ha habido quien vio en la migración tras la expulsión de España y Portugal hacia América, la posibilidad de la creencia de que este continente nuevo pudiese ser el Reino de Dios visto por los profetas. Por otra parte la decisión de prohibir la presencia judía en América no fue tan clara al principio, ya que al morir la Reina de Castilla su marido la suspendió, para reordenarla en 1518. Para mitad del siglo Xvi la ciudad de México tenía un $25 \%$ de su población blanca de ese origen con su Gran Rabino establecido (Liebman 1964). El violento arrebato antisemítico que afectó a la comunidad se produjo después, con la instalación de las ideas de la Contrareforma y de la consecuente Inquisición en la década de 1570.

En Buenos Aires, fundada en 1580, es más difícil probar cuándo ingresaron los primeros judíos, pero me atrevería a suponer que entre las huestes iniciales los debió haber, o al menos luteranos y calvinistas entre los mercenarios de Europa central como los que acompañaron a Pedro de Mendoza hecho que ya está demostrado con el caso de Utz Schmidl. Venían de formas escondidas aunque muchos lo sabían y aquí actuaban de manera más o menos pública aprovechando la situación marginal 
de la ciudad, pero no debía ser fácil y el riesgo era la vida. Las autoridades vivían quejándose de lo que sucedía pero nada hacían ellos mismos pese a que la ciudad tenía una guarnición militar en su fortaleza. La ventaja de la ciudad era que se estaba realmente lejos de la Inquisición de Lima y que la persecución inicial fue centrada en la supuesta idolatría indígena, especialmente en la región andina; lo otro era tema urbano y realmente sin apuro, como la obsesión por la presencia de luteranos en América a lo que se dedicó tanta tinta habiendo realmente tan pocos (Poderti 2005).

Por supuesto esto no quería decir que alguien no católico pudiera profesar su culto públicamente, pero en el Buenos Aires de entonces nada podría ir más lejos que una sospecha de ese tipo. Manchaba el buen nombre de su familia o sus negocios, pero lejos estaban los juicios o quemas públicas: las cosas se arreglaban con echarle la culpa a los portugueses, lo que era menos malo que ser judío. Existen docenas de cartas y escritos de las autoridades pidiendo control a sus superiores porque era obvio el ver entrar de «mucha gente portuguesa de la nación hebrea», pero la ciudad era un pulular de portugueses (Cohen 2000: 180-188; Lafuente Machain 1980). Y una Buenos Aires sin portugueses era impensable ya que el tráfico comercial y el contrabando eran multilingües como lo era la sociedad porteña, y el portugués era lengua habitual ya que era el de los puertos en que los barcos paraban y mercadeaban antes y después de estar en Buenos Aires. Es impensable el tráfico de esclavos «de Guinea» sin Portugal y Brasil (Studer 1958); y sin la entrada de esclavos es impensable Buenos Aires, finalmente un puerto negrero por excelencia.

\section{El hallazgo del Maguen David (Estrella de David)}

Durante el año 2005 se hicieron complejos y extensos trabajos de restauración arquitectónica en la casa ubicada en Defensa 350, en pleno centro histórico de la ciudad. Desde la arqueología era imposible hacer un trabajo sistemático como en tantas obras en el Centro Histórico, sólo era factible mantener visitas regulares y superevisar los trabajos. Era una conocida construcción del siglo XVIII la que tradicionalmente se le atribuía el haber sido de Bernardino Rivadavia, aunque no lo fue. Los propietarios habían demolido la mayor parte para hacer un estacionamiento años atrás, pero parte del frente subsistió y dado que casi no hay verdadera arquitectura colonial en la ciudad el sitio tiene su protagonismo en la historia porteña. Por suerte había quedado sin destruir una sección de la planta baja y del primer piso del sector ubicado al frente y es de la poca arquitectura colonial auténtica que queda en la ciudad. El estado en que se encontraba la estructura era pésimo y el trabajo de recuperación realizado fue intenso, profesional y hecho con cuidado; pero faltó la arqueología; lamentablemente por que hubiese sido fundamental para lo que vamos a detallar.

Durante los trabajos para determinar qué era antiguo y qué era moderno en el edificio para iniciar su restauración, se hicieron cateos u observaciones que fueron metódicas y cuidadosos por parte de los restauradores. En uno de ellos se encontró que en la sala de la planta baja había un piso de mosaicos graníticos puesto tras pasarse dos caños para las primeras Obras Sanitarias en los inicios de la década de 1890. Al levantarlo se observó que había otro más antiguo, hecho de baldosas cerámicas coloniales que se decidió preservar aunque con arreglos. Las baldosas estaban colocadas en líneas paralelas y tenían en sus bordes hiladas de ladrillos puestos a lo largo formando una decoración simple. Era un sistema conocido aunque poco común en una época en que era más sencillo hacerlo totalmente de ladrillos; este era un tipo de piso más caro, digno de una casa importante. Se trata de baldosas cuadradas de $27 \mathrm{~cm}$ de lado (a veces llamados ladrillos de piso), pero con la superficie superior mejor terminada que los simples ladrillos de pared. Fueron comunes hasta los inicios del siglo XIX cuando comenzaron a ser llamadas «baldosas del país» para diferenciarlas de las importadas. Dejaron de fabricarse cuando hacia 1830 empezaron a llegar baldosas rojas francesas, de Marsella y el Havre, de mejor tecnología, precio y calidad, de producción industrial. Se impusieron con notable rapidez e impusieron la costumbre hasta la actualidad de las baldosas rojas, las nuevas medían $21,5 \mathrm{~cm}$ de lado y con el sistema métrico decimal pasaron a $20 \mathrm{~cm}$ llegando así a la actualidad. 
Figura 1. Patio delantero de la casa publicado por La Nación en 1927 cuando aun existía, hoy sólo queda el bloque que da a la calle (gentileza D. Fernández).

Los restauradores procedieron a levantar el piso superior de mosaicos con su contrapiso y dejaron al descubierto el nivel antiguo, a su vez puesto sobre un contrapiso de barro. Luego y para consolidar la estructura del edifico fue levantado también el de baldosas antiguas con todo cuidado ya que la mayor parte estaban fisuradas, y dio la casualidad que una de ellas tenía grabado en la parte inferior una Estrella de David con un posible agujero para alojar una vela. Demás está decir que ninguna otra baldosa tenía nada grabado y que jamás se halló ninguna en la ciudad con nada escrito o dibujado. Descontamos que pudiera ser un gesto o acción inocente porque a alguien le podía costar, al menos una buena pelea con la Inqusicón o con quien lo viera; eran temas con los que no se jugaba. Podría haber tenido una intencionalidad agresiva, para algún día acusar a alguien, pero también era un juego peligroso: circular por la ciudad y colocarlo sin que nadie se diese cuenta es difícil de sostener ya que

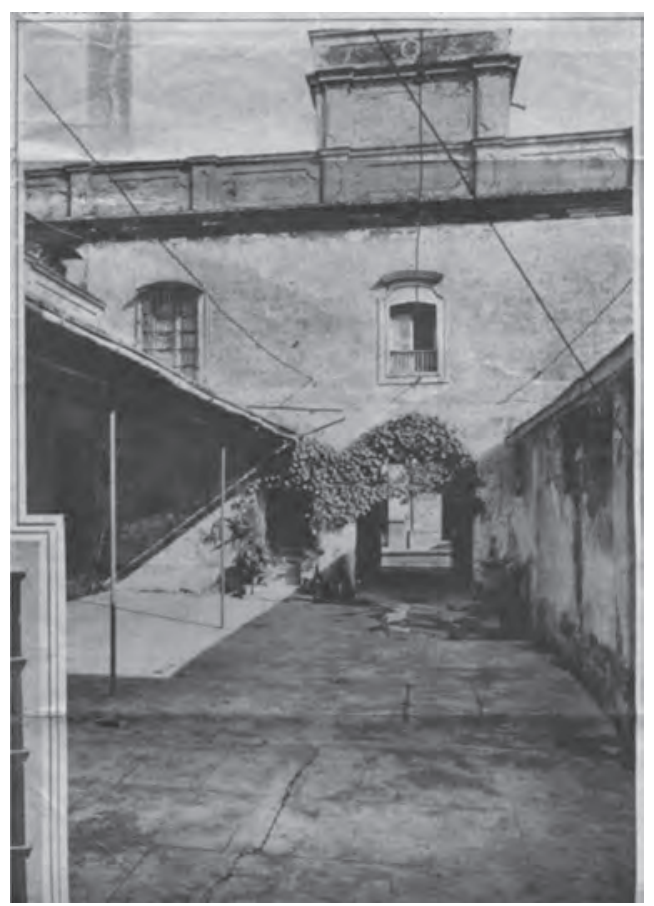
era un objeto de varios kilos que difícilmente se llevaba escondido. Es cierto que en otras ciudades como Santa Fe se hacían en la fábricas de tejas dibujos, cruces y hasta poemas en la parte superior -aunque no en las baldosas- , pero tenían un significado muy diferente y eran para ser vistas.

Lo lamentable es que, aunque se la rescató, no se registró el sitio exacto en que estaba ubicada esa baldosa en el piso. Hubiese sido más que interesante saber en dónde estaba exactamente, qué orientación tuvo, si era el centro o un rincón, si tenía las juntas tomadas o era removible. Pero no fue un trabajo controlado aunque sí de personal de confianza y ya es irremediable.

\section{EL PRIMER PROPIETARIO}

La primera pregunta que nos despierta este hallazgo es quién hizo el grabado, luego quién colocó la baldosa, después quién era el dueño de casa y si sabía en dónde estaba ese símbolo sagrado. Preguntarse si además el jefe de familia la usaba -es decir la daba vuelta para los ritos-, tal vez sea ir demasiado lejos en las suposiciones. Pero de todas las hipótesis posibles la única razonable es que quien vivía allí la puso adrede; no se trata del dibujo que un albañil hace antes de meterla al horno en que se cocían -en este caso como en todos los de la época eran en su mayoría esclavos africanos-, o que se lo hiciese a escondidas para engañar a alguien. Es algo hecho intencionalmente, difícil de ser inocente, y tanto el fabricante como quien la trasladó y colocó tenía que haberlo visto.

La historia documental nos da respuestas interesantes. En primer lugar la casa fue construida por uno de los hombres más conocidos del virreinato del Río de la Plata, Don Francisco Tellechea (también escrito Telechea y Thelechea), español, hombre del gobierno monárquico, de amplia fortuna, políticamente conservador, comprometido con su causa en tiempos de revolución y que murió ahorcado en 1812 supuestamente por haber apoyado a Martín de Alzaga en su intento de levantarse contra el movimiento por la libertad (Cutolo 1968), es decir un Conservador a ultranza. Es cierto que habían peleas personales de estos encumbrados personajes con miembros del gobierno, por ideas y por negocios, pero eso no cambia el bando en el que estaba políticamente comprometido. 


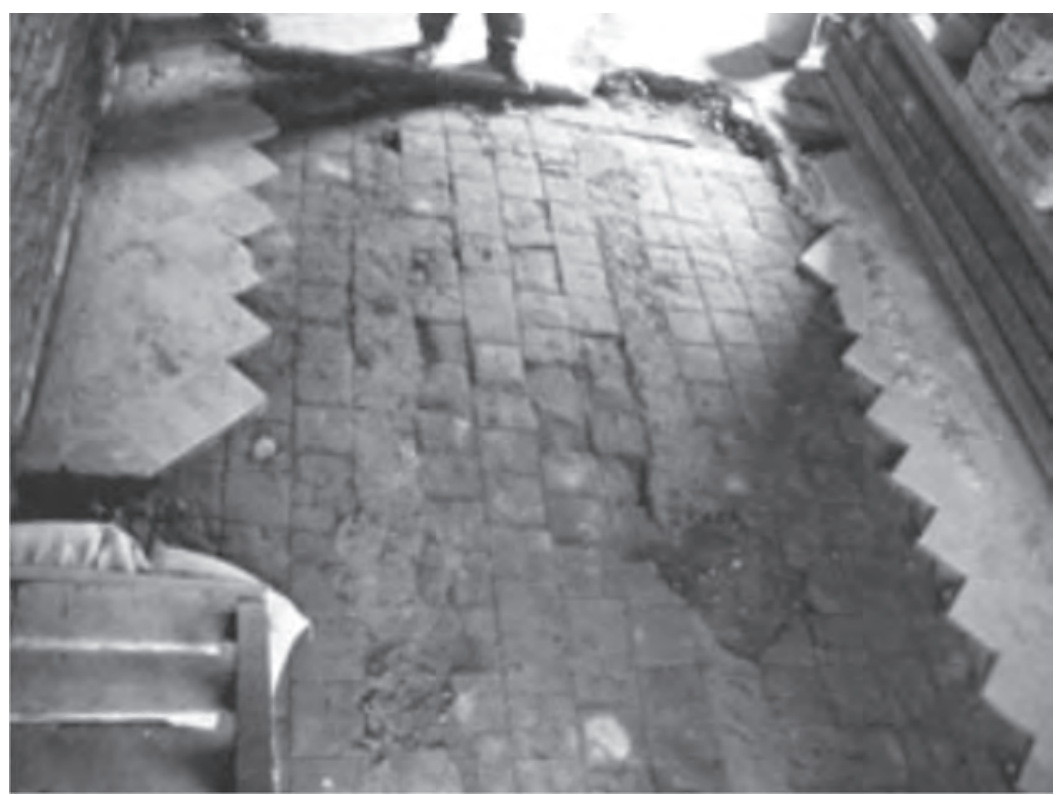

Figura 2. Piso de baldosas coloniales en el primer salón al ser descubierto en 2005, se ve aun restos del piso superior y las roturas para pasar cañerías (foto gentileza D. Fernández).

Los documentos no terminan de atribuirle a él la construcción de la casa, al menos no dicen taxativamente que la haya hecho. Era común no escriturar al construir sino al venderla al primer propietario. Pero dada la situación especial de la vida de este personaje es con él cuando se iniciaron las escrituras e inventarios. El estudio histórico de la arquitectura y el cruce de toda la información parecen indicar lo mismo: que se trata del piso original, el primero que fue hecho. Por otra parte es una obra de arquitectura típica de esos años en planta, fachada, detalles ornamentales y constructivos. Al menos en 1798 estaba en su poder y nada dice acerca de que en el sitio hubiese habido otra casa anterior. Era una vivienda de dos pisos en su frente, casa «de altos» lo que era novedad en la ciudad aunque no fue la única ni la primera. Era una verdadera casona de tres grandes patios y entrada lateral para ir a la caballeriza, es decir una vivienda de riqueza y ostentación urbana a la última moda. Un inventario de planos hechos entre 1784 y 1792 de las viviendas construidas en la ciudad, mostró que ese tipo de casas de tres patios fue sólo el 1,4\% de lo edificado. Sin duda era una minoría ya que si además le agregamos los dos pisos y el mirador, hubo sólo una docena de ellas (Schávelzon 1994). Esta casa, se haya hecho toda junta o fuese resultado de una parte delantera más tardía sobre una casa de patio preexistente -otra posibilidad analizada-, tampoco cambia lo importante en nuestro caso que es la ubicación de la sala principal en la planta baja, la que tenía la baldosa en discusión.

Figura 3. Baldosa cerámica del piso con la Estrella de David y un agujero para la vela.

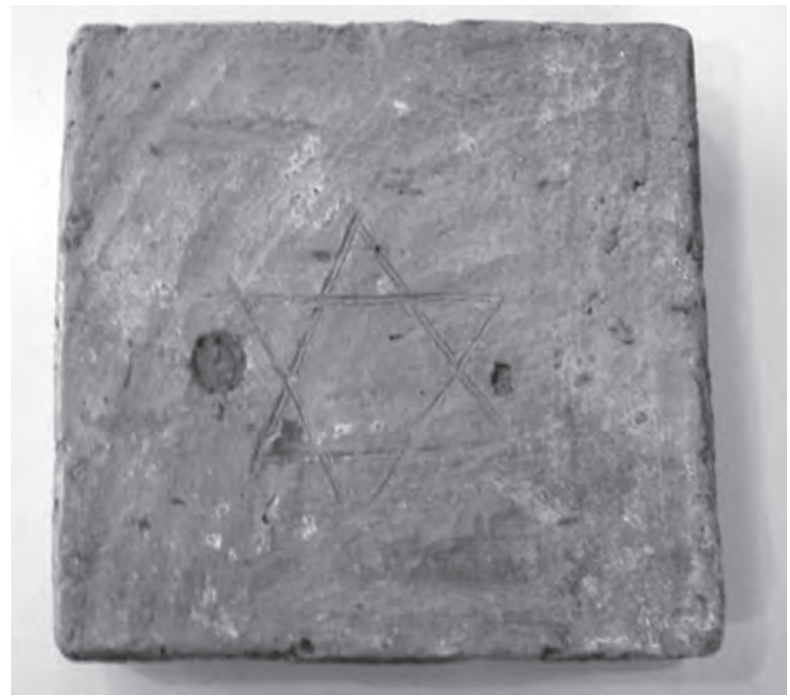


Una vez muerto Tellechea se hizo, como correspondía para la sucesión, una tasación en el mismo año de 1812, la que describió la casa con detalle e incluye el piso de baldosas. La casa luego debió tener diversos usos quizás porque la familia no podía sostenerla y por los datos se infiere que debieron alquilarla. En 1827 comenzó un proceso de traspasos, ventas y contraventas de la propiedad, que unos años más tarde pasó a ser de un grupo de familias emparentadas: los Anchorena, los Bunge y los Peña. Viendo las escrituras la evolución es así: en 1843 la compró Carlos Bunge, en 1859 pasó a manos de Genara Peña (esposa de Nicolás Anchorena) asociada con Bunge. En 1874 pasó a Estanislada Arana de Anchorena. En 1884 falleció Nicolás Anchorena y lo sucedió su hijo del mismo nombre. Los Anchorena la usaron de comercio y únicamente en todos esos años Carlos Augusto Bunge vivió allí, quien si bien era hijo de un pastor luterano su fe era la evangelista, religión a la que le dedicó gran parte de su dinero. Pero la secuencia de traspasos de la propiedad y en especial la aparición de escrituras de deudas e hipotecas más los testaferros que luego declaraban que compraban para los mismos a quienes vendían para blanquear documentos, es raro y muestra maniobras económicas que sólo servían para acrecentar sus propias fortunas. Cuán blanca era cada una de esas operaciones es algo complejo de saber. Es decir que la casa se mantuvo en el mismo círculo familiar al menos desde casi su primera venta hasta el presente (Cunietti-Ferrando 2004).

La conclusión es que la casa, la sala y el piso con la baldosa debieron estar en la construcción misma desde el primer día, es decir que todo es de 1789. Si fue removida esa baldosa-es decir si fue sacada una o más veces-, no podemos saberlo ahora ya que la pérdida del contexto original impidió observar detalles que hubieran permitido estimar si se la daba vuelta en forma recurrente. Pero sí asumimos que la casa y el piso fueron de Francisco Tellechea y que difícilmente haya sido de alguno de sus sucesores.

Este señor no era un personaje cualquiera, se distinguió como miembro del Cabildo desde 1797 donde actuó hasta 1800 como Regidor, Diputado de Policía y Fiel Ejecutor. Resultó elegido Alcalde de $2^{\circ}$ Voto en 1805 . Fue un vecino ponderado como de «lo más sano y principal de la población» (Tomasi

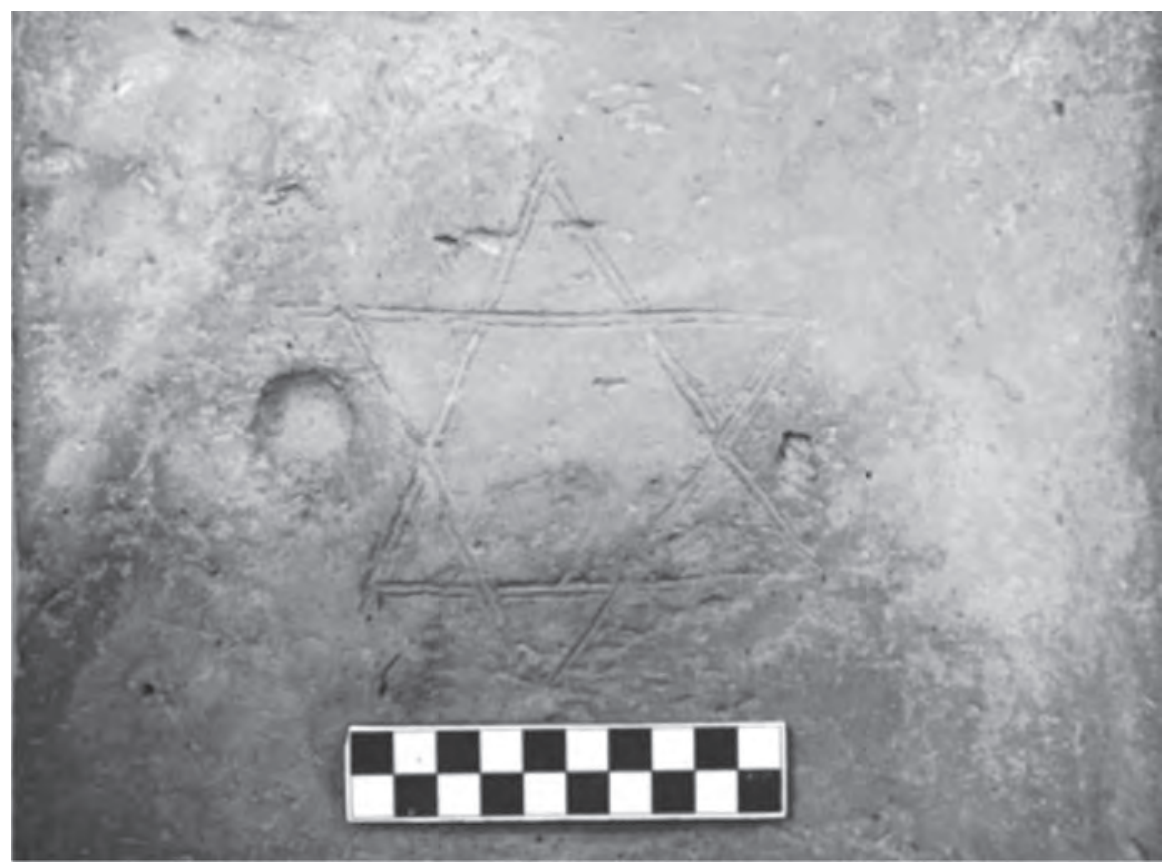

Figura 4. Detalle de la Estrella de David y el agujero para una vela grabados en la baldosa. 
2005). Siempre prestó dinero al Cabildo para gastos cuando no se contaba con efectivo por lo que fue electo Diputado Gestor Económico ante el Virrey Cisneros en 1809. A su vez fue un fuerte comerciante, reconocido entre las familias más ricas de la sociedad de su tiempo. Y desde las Invasiones Inglesas de 1806-07 y la toma del poder por Liniers de quien fue amigo, estuvo comprometido con la causa monárquica; posiblemente a su modo, pero no con la posterior Revolución, siempre sus simpatías políticas estuvieron con la monarquía. Quizás cometió el grave error de no entender la Revolución de Mayo a la que se opuso y fue exilado a La Rioja, a las minas de oro de Famatina, junto con otros españoles de alto nivel. Más tarde, en un discutido motín o alzamiento organizado por Martín de Alzaga, la que para muchos fue una trampa organizada por Rivadavia y los liberales, apoyó el movimiento junto con varios Conservadores, o de eso fue acusado, y en un juicio sumario fue sentenciado a muerte en 1812 para terminar ahorcado en la Plaza Mayor dejándose el cadáver en exhibición para escarmiento de la población. Resulta inútil en este estudio analizar ese polémico alzamiento, si siquiera existió, ya que eso ha generado largas discuciones en la historia.

Muchas veces en la bibliografía de la arquitectura de la ciudad, su casa ha sido atribuida a Bernardino Rivadavia, lo que es interesante aunque ya se ha demostrado el error (Cunietti-Ferrando 2004). Más allá de que pareciera a primera vista un mal chiste al hacerla pertenecer a quien fue uno de quienes firmó su sentencia de muerte, el error se debe tratar por la confusión debido al cambio, en enero de 1900, de la antigua numeración a la actual; la casa de Tellechea correspondía a los números 174-176 de esa calle y hoy es el 350-360. Para algunos autores Rivadavia sí habría vivido allí y es posible que la hubiese alquilado un tiempo, aunque no hay documentos o escrituras con su nombre (La Fuente Machain 1968; Taullard 1940). De todas formas la relación con Rivadavia debió existir -conflictiva o no, o porque era el secretario del Triunvirato-, ya que los minerales de Famatina en La Rioja fueron un tema que tuvieron en común. Tras su muerte Tellechea dejó un fuerte legado para hacer escuelas en La Rioja, dinero que tardó sesenta años en hacerse efectivo.

\section{LA CASA DE TELlecheA Y EL PISO DE SU SALA PRINCIPAL}

Regresando al piso de la casa y su ubicación también nos hacemos otras preguntas. Primero porque poco sabemos del salón principal, es decir de la sala que estaba en la planta baja y de su uso, el que debió ser importante; pero al haber otro aposento similar arriba, en el primer piso y ser ambos de la misma época, es complejo saber hoy su forma de uso y si nada salía de lo común de su tiempo. Era habitual equiparlas con un estrado, una zona elevada de madera para sentase en el piso sobre alfombras o con sillas de patas cortas, algún cuadro religioso o algún piano, nada más.

Las tasaciones describen bien su construcción material: el piso del salón de abajo estaba cubierto por baldosas, ya descritas como un tipo de ladrillones cuadrados que las hacían dejando el lado superior liso, lo que daba pisos bastante mejores que los hechos de simple ladrillo. Como mencionamos en este caso medían $27 \mathrm{~cm}$ de lado, lo que indica que estaban hechas antes de que se impusiera el sistema métrico decimal. Es probable que al inicio ambas salas, la de abajo y la de arriba, hayan estado cubiertas en sus pisos de manera bastante semejante, aunque luego la superior fue recubierta con tablones de madera y la de abajo con mosaicos. Según la primera tasación, hecha en 1812 por el constructor de origen portugués llamado Felis de Sousa Andrade, a resultas de la muerte de Tellechea, se dice como era cada piso: «Por $61 \frac{1}{2}$ varas piso de valdoza cortada en cal en la sala, y piso de barro debajo a 14 r.» $y$ «Por 25 varas piso de valdoza sin cortar en cal, con piso de barro debajo, tomada la junta a 9 r.» (Tomasi 2005: 40).

Si bien se trata de dos pisos sutilmente diferentes ya que uno tenía juntas de cal y el otro no, desconocemos que diferencia había entre las «cortadas» y las «sin cortar», pero es evidente que había diferencias de calidad y precio. Pero lo que importa es que estas descripciones nos hacen pensar que efectivamente los pisos son originales, de cuando se hizo la casa. 


\section{El Dibujo Y LA MANUFACTURA DE LA EsTRELla}

El tema de si la estrella está hecha cuando se hizo la baldosa o fue grabada después es algo complejo. La observación con aumento sobre la superficie cóncava de la cerámica en la que está grabada la estrella, permite ver que fue trazada de una manera simple con un instrumento cortante de dos puntas, posiblemente un tenedor de dos dientes tal como se los usaba en los siglos XVI y XVII -los de tres dientes o incluso cuatro son posteriores-, o cualquier otro instrumento punzante similar y doble. Pero por el tipo de incisión no era un cuchillo o algo cortante, eran puntas finas, paralelas pero ligeramente romas.

Sabemos que el Magen David está formado por dos triángulos superpuestos invertidos, pero para trazar su forma los cruces de las líneas tienen que pasar por abajo o por arriba de lo ya dibujado. En este caso se hizo primero un triángulo del que se nota bien dónde comienza y dónde termina ya que el artesano no pudo hacerlo coincidir en un punto y el instrumento se le patinó en la arcilla húmeda. El otro triangulo no es una línea continua si no que para evitar ese error hizo tres líneas dobles en movimientos no continuos. El trazado muestra que se lo debió hacer cuando la pasta estaba fresca y desmoldada aunque ya habiendo comenzado el secado, antes de hornearse. Esto nos explica el que haya pasta desplazada al hacer las líneas y que en algunos puntos se haya saltado el material usado como desgrasante de la cerámica. Por otra parte para que la herramienta patine y deje marcas el material cerámico debía estar bastante seco de manera irregular.

La observación con aumento muestra que la baldosa fue luego raspada con un objeto metálico, seguramente para limpiarla al descubrirla -una manera de limpiar no muy profesional-, y que la estrella fue en parte retocada. La diferencia de las líneas originales y de las recientes es clara porque se usó un cuchillo afilado y no algo de dos puntas romas paralelas como el original. De todas formas no afectó al objeto.

Todo esto nos abre interrogantes ya que si tenía la intencionalidad simbólica que presumimos, debió hacerse en el fabricante, luego hornearse y dejarla enfriar, y después trasladarla a la ciudad para ser luego colocada en el piso. El tema es complejo en ese Buenos Aires colonial ya que implica muchas operaciones que ocultar y por lo tanto el compromiso de más de una persona; o que había temas organizados con carriles aceitados que ni siquiera imaginamos.

Finalmente queda el agujero de unos $2,5 \mathrm{~cm}$ de diámetro, al que en las fotos hemos ubicado a la izquierda pero bien podría ir a la derecha ya que no tiene orientación. Del otro lado y casi simétrico hay un agujero menor, pero fue el producto de una burbuja interior que reventó en la cochura y aun hoy el borde está quebrado limpiamente; en realidad hay varios de ellos como en cualquier baldosa. El agujero circular tiene evidencias de abrasión y pátina de exposición en su superficie, aunque por el raspado el fondo debió haber sido limpiado al encontrarlo; un análisis químico de su interior podría haber aportado datos interesantes acerca de si había restos de cera o sebo pero era tarde al identificarlo. Sí los bordes tienen una pátina de uso lo que sólo da el tiempo y esta se une con la que cubre parcialmente a la estrella.

\section{La Estrella de David en el Siglo XVIII}

Llama la atención el uso de este símbolo en el siglo XviII y no el Candelabro de Siete Velas (la Menorah), mucho más reconocido y tradicional. Quizás por ser la estrella el símbolo actual del Estado de Israel y estar en su bandera, y que desde los inicios del siglo XIX se lo identifica sólo con la comunidad judía, haga que no nos parezca extraño. Pero la historia indica que el símbolo de la estrella de seis puntas asociada al rey David en la Biblia, no representaba a su religión ni sabemos la forma exacta que tenía en aquellos tiempos. Con el tiempo esta aparece en diferentes textos sagrados en especial en Praga y se fue difundiendo pero nunca reemplazando al candelabro; la estrella surgió y se difundió entre los siglos XI y XIV. En el siglo siguiente se hizo más común y según 
la tradición fue en el centro de Europa en donde se transformó en símbolo oficial en el siglo XVII. En los guetos de Alemania, la vieja Checoslovaquia y Austria fue desde donde se lo fue difundiendo y adoptando por las demás comunidades europeas. No es un tema claro ya que aparece en lápidas funerarias anteriores y en templos; era algo que representaba pero sin ser un símbolo con la fuerza de identidad que tiene actualmente.

Esta baldosa, de aceptar los supuestos de su manufactura hacia 1789 con un objetivo simbólico religioso es una aparición temprana en el continente; y que el símbolo haya llegado desde Europa en manos de un inmigrante parece muy probable. Precisamente fueron los tiempos de la Revolución Francesa y de la Ilustración los que llevaron a que cada grupo religioso o civil generara un símbolo particular que lo identifique ante los demás. Por otra parte es cierto que los criptojudíos no necesitaban mucho para ejercer su culto en América:

«Eran una diáspora sin clero, sin cabeza visible, sin ciudad santa, sin escuela teológica organizada, que quedó unida por la cadena de hierro de los deberes religiosos comunes. Los hebreos trajeron consigo sólo su religión y no precisaron para su culto de la aparatosa maquinaria necesaria al rito y la liturgia externos: les bastaron la fidelidad al recuerdo de su raza, la profesión de su fe y la práctica de la Ley» (Trabulse 1982).

América era un ambiente hostil y el ocultamiento fue la forma que tuvieron durante siglos de sobrevivir dentro de ella y prosperar, pero en silencio. Quizás una simple baldosa con una vela enfrente, puesta en un piso en la que sólo una persona o su entorno familiar más cercano sabían lo qué había abajo, era suficiente. Jorge Luis Borges lo diría en otras palabras «[...] desde su nada/ sigue erigiendo a Dios con la palabra» (Borges 1976: 119).

Nos queda otra pregunta si queremos ser los abogados del diablo: ¿pudo haber sido símbolo de otra cosa? Recordemos que los movimientos esotéricos del siglo xvIII resignificaron la estrella tomándolo de Egipto. La Francmasonería también lo usó a fines de ese siglo, los Rosacruces incluso cien años antes, y desconocemos si las agrupaciones masónicas en Buenos Aires, como la Logia Lautaro creada por San Martín y a la que pertenecía la intelectualidad libertadora -aunque años más tarde-, tuvo manera de identificarse, pero eso es posterior ya que José de San Martín llegó a la Argentina en el mismo año en que Tellechea fue ajusticiado.

\section{¿Pudo haber un final diferente?}

No sabemos con certeza si Tellechea fue un criptojudío, menos si ese piso y su baldosa eran de él, y si lo sabía, y si lo usaba, sólo lo suponemos con evidencias a favor de que sí. Pero por eso la arqueología es cauta.

La suma de todas las evidencias nos lleva a pensar sobre su muerte y si ésta tuvo relación también con su forma de vivir, con su religión, no sólo con la política o con Rivadavia o el Triunvirato. La historia oficial recoge que cuando los sucesos de Mayo se fueron polarizando, es decir que se hizo cada vez más claro por si no lo fue desde el inicio, que se trataba de una verdadera revolución contra el gobierno español -estuviese o no España ocupada por Francia, se aprovechara o no la ocasión-, algunos se sintieron traicionados. Más lo pudo haber sentido así un gran comerciante español como Tellechea que había participado del gobierno y tenía sus amistades y compromisos. Para los que habían apoyado los sucesos de Mayo porque les convenía para sus negocios, una cosa era lograr cierta autonomía debida a la ocasión y otra diferente era un cambio radical. Discutir esto es tema complejo y nuestros historiadores vienen haciéndolo desde hace un siglo, ya lo dijimos. Lo concreto en este caso es que alrededor de uno de los personajes destacados de la sociedad de su tiempo, Martín de Alzaga, se formó un grupo de descontentos de los que desconocemos el grado de organización al que llegaron; uno de los acusados fue Tellechea (Lozier Almazán 1998; Williams Alzaga 1971). Una supuesta denuncia desbarató todo y con velocidad fueron acusados, sentenciados y ajusticiados como se hacía 
en su tiempo, sin muchos derechos ni necesidad de pruebas, era un castigo ejemplar a lo más alto de la sociedad. Tellechea el 11 de julio firmó su testamento y treinta días después fue ajusticiado quedando su cadáver colgado de la horca.

Tellechea en vida se casó en tres oportunidades: la primera en 1792 con la porteña Mathea Gerónima Caviedes; en segundas nupcias en 1805 con Manuela Léxica y Vera, y finalmente con Ana Ballesteros. Esto viene a colación por que María Calixta Tellechea Caviedes, hija de su primer matrimonio, se casó con Juan Martín de Pueyrredón, es decir con uno de los miembros del Triunvirato que firmó la sentencia de muerte de su padre; ella tenía al casarse 15 años. Esto demuestra que mirar el mundo pasado desde hoy es muy difícil.

La gran pregunta que a uno se le viene a la cabeza al ver el cruce de este objeto con la información sobre la religión de Tellechea, es: ¿pudo jugarle en contra alguna sospecha de ser judío? Si lo era resulta trágico que sólo un año después de su muerte fue extinguido el Tribunal de la Inquisición en el Río de la Plata, aunque el libre ejercicio de la religión para los judíos en la ciudad de Buenos Aires tuvo que esperar la firma de la Constitución de 1852, lo que hizo Buenos Aires en 1861.

\section{El testamento de Francisco Tellechea}

Si fue o no criptojudío no lo sabemos, lo dijimos, y es difícil de demostrar una u otra cosa, precisamente para eso son los secretos. Lo que sí sabemos es que siempre se comportó como un verdadero creyente católico. Pudo o no haber ido a misa y participar del culto regular -no lo sabemos-, lo que en ese momento hubiese dado que hablar si no lo hacía pero bien sabemos que en general la actitud con los hombres era mucho más displicente a la que se tenía con las mujeres.

Uno esperaría que dijera algo en su testamento, al fin de cuentas su escrito final y la situación era de extrema violencia; que declarase ante esa circunstancia la verdad. Pero dijese lo que dijera nada iba a cambiar su sentencia de muerte aunque sí a teñir de aun más odios a su familia. ¿Qué decidió hacer? Imposible saberlo si no sabemos demasiado. Pero hemos aprendido que para hacer historia, como para hacer arqueología, hay que ser escéptico, leer entre líneas y jamás aceptar lo obvio por propia obviedad. Leer su testamento es un ejemplo de creencia cristiana absoluta rayando en lo obsesivo pero no lejos de lo habitual; pero también puede ser que el escribano con que lo hizo, con un reo sentenciado, bien pudo haberle dado una forma habitual o incluso un papel encabezado en la forma de costumbre para que lo complete y firme. Lo concreto es lo que dice en la introducción:

«En el nombre de la Santísima Trinidad Padre, Hijo, y Espíritu Santo, tres personas distintas, y un solo Dios Verdadero [...] creyendo como verdaderamente creo todos los misterios de nuestra Santa Fe Católica, en cuya creencia quiero, y proyecto vivir, y morir, como fiel Cristiano, y verdadero Católico, y espero en la divina majestad que ha de tener misericordia de mis culpas, y pecados por los meritos de nuestro señor Jesucristo, y de su Madre Santísima, a quien elijo por abogada, para que con el Ángel de mi guarda y Santo de mi nombre y demás es mi devoción me asistan en el tremendo tribunal de Dios, hago, ordeno y establezco este mi testamento y ultima voluntad en la forma siguiente - Primeramente mando y encomiendo mi alma a Dios nuestro Señor que la creó, y redimió con el inestimable precio de su Sangre, suplicando a su Divina Majestad la lleve consigo a su gloria para donde fue creada y el cuerpo mando a la tierra de que fue formado» (Tomasi 2005).

\section{CONCLUSIONES}

Sabemos, y ya lo han dicho otros, que es muy complejo «presentarle al lector un enigma para terminar confesando a los lectores que no se posee la clave para resolverlo» (Mangenest 2009). Pero no tenemos otra alternativa.

La arqueología puede dar sorpresas. Hace unos quince años se comenzó en Argentina a descubrir la cultura material del sexo, luego hace diez la presencia de los afroargentinos, sus resistencias 
culturales y la conservación de las religiones de origen en prácticas a veces mixturadas con lo indígena local, sucesos silenciados por la historia oficial. Esos hallazgos fueron pequeñas revoluciones en el campo del conocimiento arqueológico. Ahora surge el tema de la presencia judía en tiempos de prohibición. Y se sigue avanzando con conocimientos del pasado para darle voz a los silenciados, los perseguidos, los marginados y los olvidados. Como tarea para la ciencia no es poco importante oír los múltiples susurros que nos hablan a través del tiempo y rescatarlos.

\section{Agradecimientos}

Agradecemos el haber facilitado el acceso a la vivienda y la entrega de los objetos recuperados al arquitecto Daniel Fernández al igual que toda la documentación de los trabajos en el sitio, al Centro de Arqueología Urbana. Los estudios y obras fueron hechos bajo su dirección por Alejandro Ruiz Luque, Alejandra Lizaso, Ana Hollmann y Felipe Monk. La investigación histórica fue hecha por Jorge Tomasi.

\section{BibliografíA}

AVNI, Haim

1992 Judios en América, cinco siglos de historia. Madrid: Ediciones Mapfre.

BOHM, Gunter

1992a Los sefardíes en los dominios holandeses de América del Sur y del Caribe, 1630-1750. Frankfurt: Vervuert Verlag.

1992b «El supuesto origen judío de Cristóbal Colón, una reevaluación». Lateinamerika Studien, vol. 30. Vervuet Verlag.

BORGES, Jorge Luis

1976 «Baruch Espinoza», La moneda de hierro. Buenos Aires: Emecé.

CANCLINI, Arnoldo

1992 La fe del Descubridor. Buenos Aires: Editorial Plus Ultra.

COHEN, Mario E.

2000 América colonial judía, CIDISEF, Buenos Aires.

CUTOLO, Vicente

1968 Nuevo Diccionario Biográfico Argentino. Buenos Aires: Editorial Elche.

CUNIETTI-FERRANDO, Arnaldo

2004 «La casa que habitó en Buenos Aires Bernardino Rivadavia». Historias de la Ciudad, № 27: 31-38, Buenos Aires

EMMANUEL, Isaac y S.

1970 History of the Jews of the Netherland Antilles, 2 vols, Cincinnati: American Jewish Archives.

GARCIA DE PRODIAN, Lucía

1966 Los judios en América, sus actividades en Nueva Castilla y Nueva Granada en el siglo XVII. Madrid: Consejo Superior de Investigaciones Científicas.

JOHNSON, Paul

1991 La historia de los judíos. Buenos Aires: Javier Vergara Editor.

LAFUENTE MACHAIN, Ricardo de

1968 El barrio de Santo Domingo, Cuadernos de Buenos Aires. Buenos Aires: Municipalidad de la Ciudad.

1980 [1931] Los portugueses en Buenos Aires, siglo XVII. Buenos Aires: Municipalidad de la Ciudad.

LEWIN, Boleslao

1939a Los marranos, un intento de definición. Buenos Aires: Colegio Libre de Estudios Superiores.

1939b El judío en la época colonial, un aspecto de la historia rioplatense. Buenos Aires: Colegio Libre de Estudios Superiores.

1967 La inquisición en Hispanoamérica: judíos, protestantes y patriotas. Buenos Aires: Editorial Paidós. 
LIEBMAN, Seymour

1964 Guide to Jewish references in the Mexican colonial era. Filadelfia: University of Pennsylvania Press.

1971 Los judíos en México y América Central. México: Siglo XXI.

1984 Réquiem por los olvidados: los judíos españoles en América 1493-1825. Madrid: Editorial Altalena..

LOZIER ALMAZAN, Bernardo

1998 Martín de Alzaga. Buenos Aires: Ed. Ciudad Argentina.

MEDINA, José Toribio

1945 El Tribuna del Santo Oficio de la Inquisición en las Provincias del Plata. Buenos Aires: Editorial Huarpes.

PODERTI, Alicia

2005 Brujas andinas: la inquisición en la Argentina. Sydney: Cervantes Publishing.

ROTH, Cecil

1959 A history of the marranos. Nueva York: Meridian Books.

SCHAVELZON, Daniel

1994 «La casa colonial porteña: notas preliminares sobre tipología y uso de la vivienda». Medio ambiente y urbanización 46: 68-83, Buenos Aires.

2003 Buenos Aires Negra, arqueología histórica de una ciudad silenciada. Buenos Aires: Ediciones Emecé.

STUDER, Elena S. F. de

1958 La trata de negros en el Río de la Plata durante el siglo XVIII. Buenos Aires: Universidad de Buenos Aires.

TAULLARD, Alfredo

1940 Los planos más antiguos de Buenos Aires. Buenos Aires: Ediciones Peuser.

TOMASI, Jorge

2005 Informe histórico; detalle del estudio de Defensa 350. Buenos Aires. www.iaa.fadu.uba.ar/cau/?p=2515

TRABULSE, Elías

1982 «Proemio» a Alfonso Toro, Los judíos de la Nueva España, documentos del siglo XVI correspondientes al ramo de Inquisición. México: Fondo de Cultura Económica.

WILLIAMS ALZAGA, Enrique

1971 Martín de Alzaga en la reconquista y en la defensa de Buenos Aires (1806-1807). Buenos Aires: Ediciones Emecé.

WINITZER, Arnold

1966 Ou judeus no Brasil. San Pablo: Editora de la Universidad de Sao Paulo. 